\title{
Aspectos biométricos de frutos e sementes de Caesalpinia ferrea Mart. ex Tul. provenientes do semiárido baiano
}

\author{
Reginaldo Muniz da Silva ${ }^{1}$, Adriana Dias Cardoso ${ }^{1}$, Fabrício Vieira Dutra ${ }^{1}$, Otoniel \\ Magalhães Morais ${ }^{1}$ \\ ${ }^{1}$ Universidade Estadual do Sudoeste da Bahia, Campus Vitória da Conquista, Bahia, Brasil. E-mail: muniz-la@ hotmail.com, \\ adriuesb@yahoo.com.br, fabriciovieira94@hotmail.com,omgsmorais@gmail.com,
}

Recebido: 13/01/2017; Aceito: 21/08/2017.

\begin{abstract}
RESUMO
A biometria de frutos e sementes fornece informações para a conservação e exploração da espécie, permitindo usá-los de forma eficaz e sustentável. Além disso, é considerado instrumento importante para detectar a variabilidade genética dentro de populações e relações com fatores ambientais. Assim, o objetivo do trabalho foi avaliar a morfometria de frutos e sementes da espécie Caesalpinia ferrea Mart. ex Tul. provenientes de Vitória da Conquista, BA. Para avaliação da biometria foram coletados 100 frutos maduros de diferentes árvores matrizes. As características avaliadas foram: comprimento, largura e espessura medidos na linha mediana dos frutos e das sementes com auxílio de um paquímetro digital. O comprimento, largura e espessura média encontrada para os frutos foram de $(8,0 \pm 1,4 \mathrm{~cm}) ;(26,2 \pm 2,6 \mathrm{~mm})$ e $(11,2 \pm 2,2 \mathrm{~mm})$, respectivamente. A massa dos frutos variou de $8,6 \mathrm{a}$ $24,2 \mathrm{~g}$, sendo que a maioria dos frutos (47\%) apresentou valores entre 10,2 e 13,2 g. O número de sementes por fruto variou de duas a sete, sendo verificada média de cinco sementes por fruto. Ocorreu variação quanto à massa de sementes encontradas por fruto, havendo uma amplitude de $1,70 \mathrm{~g}$ entre o valor mínimo e máximo encontrado. Com relação à biometria das sementes, a média de comprimento, largura e espessura encontrada foi de 10,2 $\pm 0,9 \mathrm{~mm}$; 7,1 $\pm 0,8 \mathrm{~mm}$ e $4,0 \pm 0,5 \mathrm{~mm}$, respectivamente. Os valores biométricos observados no estudo são indicativos que os frutos e sementes de Caesalpinia ferrea apresentam variabilidade genética em suas características avaliadas.
\end{abstract}

Palavras-chave: Pau ferro, Espécie florestal, Morfologia.

\section{Biometric aspects of fruit and seed of Caesalpinia ferrea Mart. ex Tul. from semiarid baiano}

\begin{abstract}
The biometry of fruits and seeds provides information for the conservation and exploitation of the species, allowing rational search, effective and sustainable use. In addition, it is considered an important tool to detect genetic variability within populations and relationships with environmental factors. Thus, the objective of this work was to evaluate the fruit and seed morphometry of Caesalpinia ferrea Mart. ex Tul. cultivated in Vitória da Conquista, BA. To evaluate the biometry, one hundred mature fruits of different matrix trees were collected. The length, width and thickness were evaluated in the fruit and seed median line with the aid of a digital caliper. The average length, width and thickness found for the fruits were $(8.0 \pm 1.4 \mathrm{~cm}) ;(26.2 \pm 2.6 \mathrm{~mm})$ and $(11.2 \pm 2.2 \mathrm{~mm})$ respectively. Fruit mass ranged from 8.6 to $24.2 \mathrm{~g}$, and a higher proportion of fruits (47\%) presented values ranging from 10.2 to $13.2 \mathrm{~g}$. The number of seeds per fruit varied from two to seven, being verified average of five seeds per fruit. Variation in the mass of seeds found per fruit occurred, with and amplitude of $1.70 \mathrm{~g}$ between the minimum and maximum values. With respect to seed biometry, the mean length, width and thickness found was $10.2 \pm 0.9 \mathrm{~mm} ; 7.1 \pm 0.8 \mathrm{~mm}$ and $4.0 \pm 0.5 \mathrm{~mm}$, respectively. The biometric values observed in the study are indicative that the fruits and seeds of Caesalpinia ferrea show genetic variability in their evaluated characteristics.
\end{abstract}

Key words: Pau ferro, Forest species, Morphology. 


\section{Introdução}

Caesalpinia ferrea Mart. ex Tul. (Fabaceae) é uma espécie arbórea distribuída por toda a região tropical do Brasil (GALDINO et al., 2007) e, neste contexto, indivíduos com até 30 metros de altura (CAVALHEIRO et al., 2009) são encontrados na região da Caatinga brasileira (COELHO et al., 2010).

Por ser uma árvore tolerante a áreas abertas, o pau ferro pode ser utilizado em programas de reflorestamento de áreas degradadas ou como vegetação marginal dos cursos de água, controlando a erosão e o assoreamento dos rios (SANTOS et al., 2010). Ademais, apresenta grande importância na ornamentação de locais públicos, construção civil e marcenaria. Seus frutos são frequentemente utilizados na medicina popular, por serem considerados antidiarreicos, anticatarrais e cicatrizantes (MAIA, 2004). Suas sementes também apresentam grande importância, pois servem como fonte de propagação e manutenção da espécie (NOGUEIRA et al., 2010).

A caracterização biométrica em plantas consiste na avaliação de aspectos morfológicos do vegetal. Neste contexto, a caracterização de frutos e sementes tem grande importância. Através do conhecimento do peso e de padrões morfológicos das sementes é possível traçar uma estratégia para maximizar a uniformização de emergência das plântulas, favorecendo a obtenção de mudas de tamanho semelhante ou de maior vigor (CARVALHO; NAKAGAWA, 2000).

De maneira geral, a técnica de biometria possibilita a comprovação de grande variabilidade genética entre os gêneros arbóreos (LOPES, 2007; MATHEUS \& LOPES, 2007; OLIVEIRA et al., 2011; PEREIRA et al., 2011). Neste sentido, as informações obtidas pela biometria podem auxiliar na conservação e exploração racional dos recursos naturais com valor econômico, no direcionamento de trabalhos de melhoramento vegetal $\mathrm{e}$ também na distinção entre espécies do mesmo gênero
(BATTILANI et al., 2011; BEZERRA et al., 2014; CHRISTRO et al., 2012).

É relevante que se tenha o máximo de informações sobre o aspecto comportamental do pau ferro em diferentes localidades, pois as variações nos padrões morfológicos de um indivíduo estão relacionadas ao fator genético e à influência das condições ambientais em que este se encontra.

Desta forma, o presente trabalho teve como objetivo realizar a caracterização morfológica de frutos e sementes de árvores de pau ferro proveniente do semiárido baiano.

\section{Material e Métodos}

O trabalho foi realizado no ano de 2015, na Universidade Estadual do Sudoeste da Bahia (UESB), campus de Vitória da Conquista - BA, localizada a $14^{\circ} 51^{\prime} 58^{\prime \prime}$ de Latitude Sul e $40^{\circ} 50^{\prime} 22^{\prime \prime}$ de Longitude Oeste, em altitude média de $941 \mathrm{~m}$ e clima conforme classificação de Köppen do tipo Cwa (tropical de altitude). A temperatura média anual da região é de $20,2^{\circ} \mathrm{C}$ e a precipitação anual de $733,9 \mathrm{~mm}$ (INMET, 2017).

Para a caracterização morfológica foram utilizados dez frutos sadios e maduros de pau-ferro coletados, aleatoriamente, na copa de dez árvores matrizes, localizadas no campus da UESB em Vitória da Conquista, durante o mês de novembro de 2015.

Após a coleta, foi formada uma amostra composta de cem frutos e cem sementes sendo, posteriormente, acondicionados em sacos plásticos devidamente identificados e encaminhados ao Laboratório de Tecnologia e Produção de Sementes para análise.

Com o auxílio de um martelo foi retirada as sementes de dentro dos frutos para, posteriormente, proceder-se às análises de biometria.

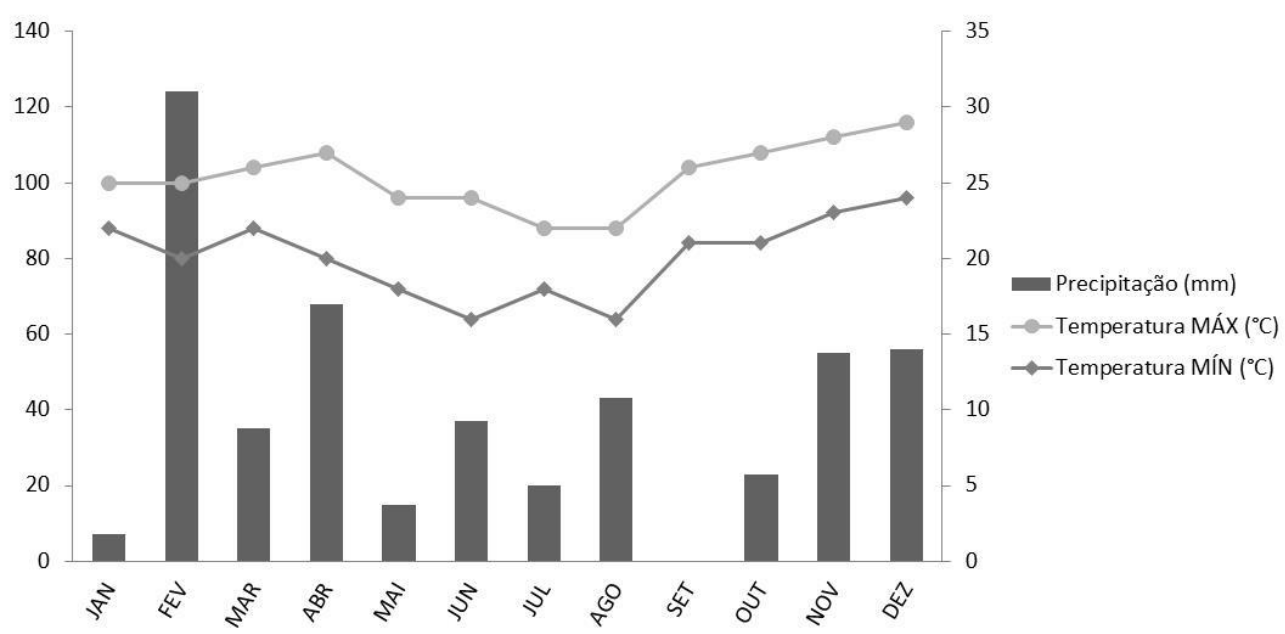

Figura 1. Precipitação e temperatura mínima e máxima mensal durante o ano de 2015 em Vitória da Conquista, BA (INMET, 2017). 
As características biométricas avaliadas que envolveram os frutos e de frutos foram: comprimento determinado da base até o ápice, com auxílio de régua graduada; largura e espessura medidas na linha mediana dos frutos, utilizando-se paquímetro digital com precisão de $0,05 \mathrm{~mm}$; massa do fruto, registradas utilizando-se balança com precisão de 0,001 g em cada fruto. As características biométricas avaliadas para as sementes foram: comprimento, largura, espessura e massa de sementes, utilizando-se a mesma metodologia adotada para os frutos e número de sementes por fruto ${ }^{-1}$, determinada por meio da contagem das sementes em cada fruto.

Os dados obtidos foram submetidos à análise descritiva, obtendo-se as respectivas médias e desvio padrão. Os dados foram classificados por meio de distribuição de frequência e plotados em histogramas de frequência, o número e intervalos de classe determinados de acordo com a fórmula de Sturges $(\mathrm{k}=$ $1+3,322(\log 10 \mathrm{n}))$, utilizando-se planilha eletrônica do Microsoft Office (Excel 2010).

\section{Resultados e Discussão}

O comprimento, largura e espessura média encontrada para os frutos foram de $8,0 \pm 1,4 \mathrm{~cm} ; 26,2 \pm$ 2,6 $\mathrm{mm}$ e 11,2 $\pm 2,2 \mathrm{~mm}$ respectivamente (Tabela 1). Em trabalho realizado no estado do Rio Grande do Norte buscando avaliar a biometria de frutos de Caesalpinia ferrea Mart. ex Tul. foram observados resultados diferentes aos encontrados no presente trabalho, com comprimento, largura e espessura média de $8,61 \mathrm{~cm}, 17,48 \mathrm{~mm}$ e 7,01 $\mathrm{mm}$ respectivamente (CÂMARA et al., 2008), demonstrando que a morfologia pode ser influenciada pelas condições edafoclimáticas de cada local de cultivo.

Tabela 1. Comprimento (cm), espessura (mm) e largura (mm) de cem frutos oriundos de dez árvores de pau ferro (Caesalpinia ferrea Mart. ex Tul) localizados em Vitória da Conquista - BA, 2015.

\begin{tabular}{lccc}
\hline Parâmetro & $\begin{array}{c}\text { Comprimento } \\
(\mathrm{cm})\end{array}$ & $\begin{array}{c}\text { Largura } \\
(\mathrm{mm})\end{array}$ & $\begin{array}{c}\text { Espessura } \\
(\mathrm{mm})\end{array}$ \\
\hline Média & $8,0 \pm 1,4$ & $26,2 \pm 2,6$ & $11,2 \pm 2,2$ \\
Mediana & 7,8 & 26,1 & 11,3 \\
Variância & 1,89 & 6,84 & 4,94 \\
\hline CV $(\%)$ & 17,1 & 10 & 19,9 \\
\hline
\end{tabular}

Da mesma forma Ferreira e Barreto (2015), trabalhando no estado de Sergipe com frutos de Caesalpinia echinata Lam, espécie pertencente à mesma família, verificaram resultados diferentes, com comprimento médio de $6,16 \mathrm{~cm}$ (variando de 4,01 a $6,70 \mathrm{~cm}$ ), largura média de 23,5 mm (variando de 15,0 a
24,4 mm) e espessura média de 21,1 mm (variando de $1,1 \mathrm{~mm}$ a 3,0 $\mathrm{mm}$ ), indicando que frutos de Caesalpinia ferrea Mart. ex Tul. apresentam menor tamanho.

Todas as características avaliadas apresentaram baixo desvio padrão, no entanto, o menor valor foi observado para a característica comprimento, indicando que, possivelmente, esta seja uma variável de menor variabilidade em relação às demais.

Observou-se que as classes mais representativas quanto ao número de frutos para as características de comprimento, largura e espessura, foram respectivamente: 7,0 a $7,7 \mathrm{~cm}(21,5 \%), 25,8$ a $27,7 \mathrm{~mm}$ $(34,7 \%)$ e 10,3 a $12,0 \mathrm{~mm}(45 \%)$ (Figura 2).

Com efeito, de acordo com Gusmão et al. (2006), espécies arbóreas tropicais, geralmente, apresentam grande variabilidade com relação ao tamanho dos frutos, logo, tal fato pode justificar a grande amplitude verificada nas características. Em estudo realizado com espécie da mesma família (Cassia grandis L. f.), a classe de frequência mais representativa foi de 20,9$27,7 \mathrm{~cm}$ (24\%) para o comprimento, de 38,17 - 40,43 $\mathrm{mm}(28 \%)$ e de $40,44-42,69 \mathrm{~mm}(28 \%)$ para a largura, indicando que pode ocorrer variabilidade quanto às características estudadas também em outras espécies (BEZERRA et al., 2012).

A massa dos frutos variou de 8,6 a 24,2 g, sendo que uma maior proporção de frutos (47\%) apresentou valores variando entre 10,2 e 13,2 g (Figura 3). A média de massa dos frutos foi de 12,3 $\pm 3,21 \mathrm{~g}$. Resultados diferentes dos obtidos neste trabalho foram observados por Galdino et al. (2007), os quais, descrevendo biometricamente frutos de Caesalpinia ferrea Mart. ex Tul. em região de clima equatorial, observaram média $5,27 \mathrm{~g}$ de sementes por frutos e dados variando de 3,55 a 7,30g.

Com relação à biometria das sementes, a média de comprimento, largura e espessura encontrada foi de 10,2 $\pm 0,9 \mathrm{~mm} ; 7,1 \pm 0,8 \mathrm{~mm}$ e $4,0 \pm 0,5 \mathrm{~mm}$, respectivamente (Tabela 2 ). A diferença no tamanho das sementes dentro de uma mesma espécie pode estar associada com o ambiente onde a planta mãe está inserida. Se durante o período de desenvolvimento da semente os recursos necessários para a sua formação (água, radiação solar e nutriente) forem escassos, a planta mãe provavelmente dará origem a sementes com os mais variados padrões morfológicos, não possuindo uniformidade em seus tamanhos.

Das características avaliadas para as sementes, a espessura foi a que apresentou menor desvio padrão, enquanto o maior valor foi observado para o comprimento, indicando que, possivelmente, estas sejam características de menor e maior variabilidade, respectivamente. 

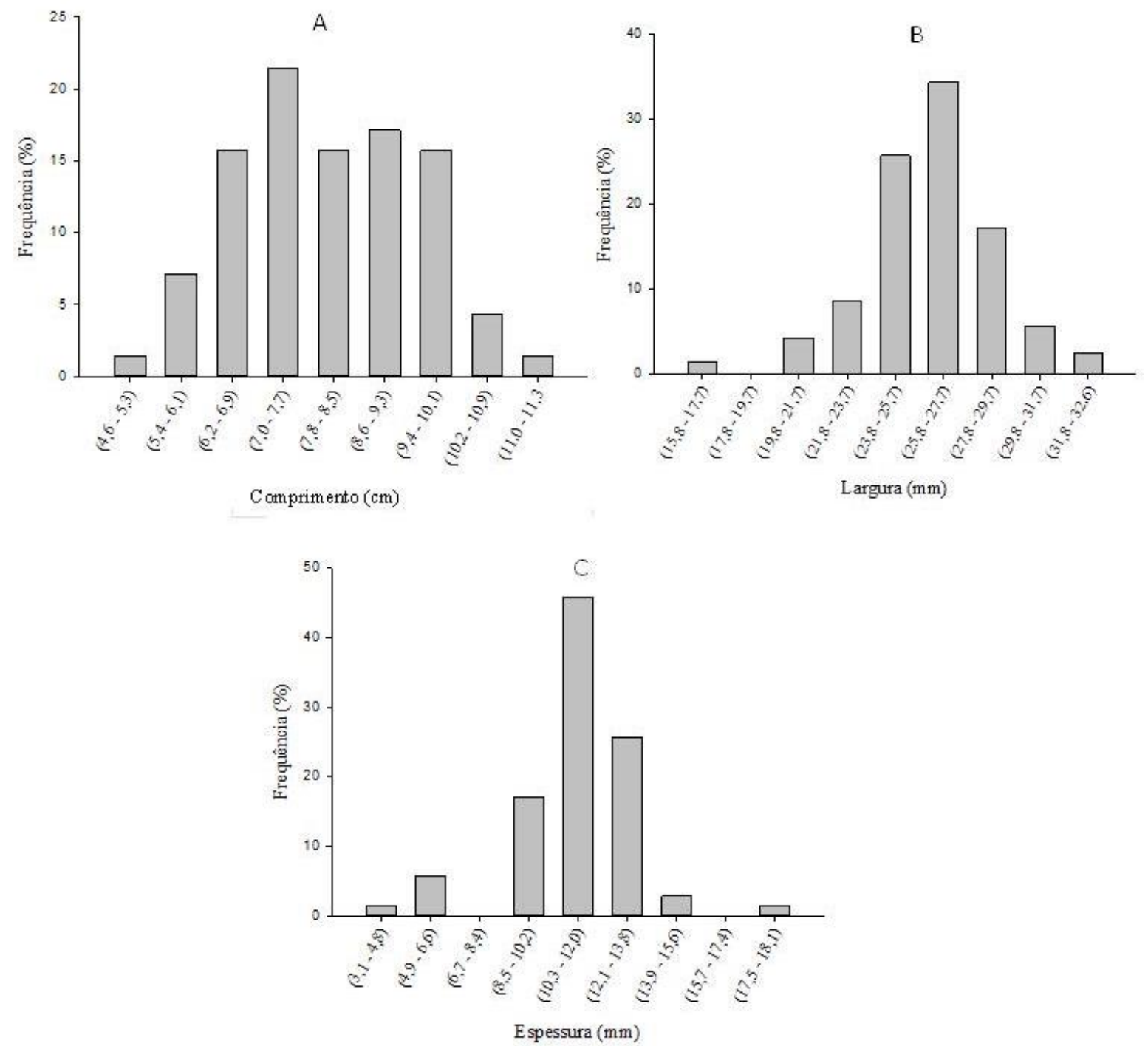

Figura 2. Histogramas de frequência (\%) para as características de comprimento (A), largura (B) e espessura (C) de frutos de pau ferro, localizados em Vitória da Conquista - BA, 2015.

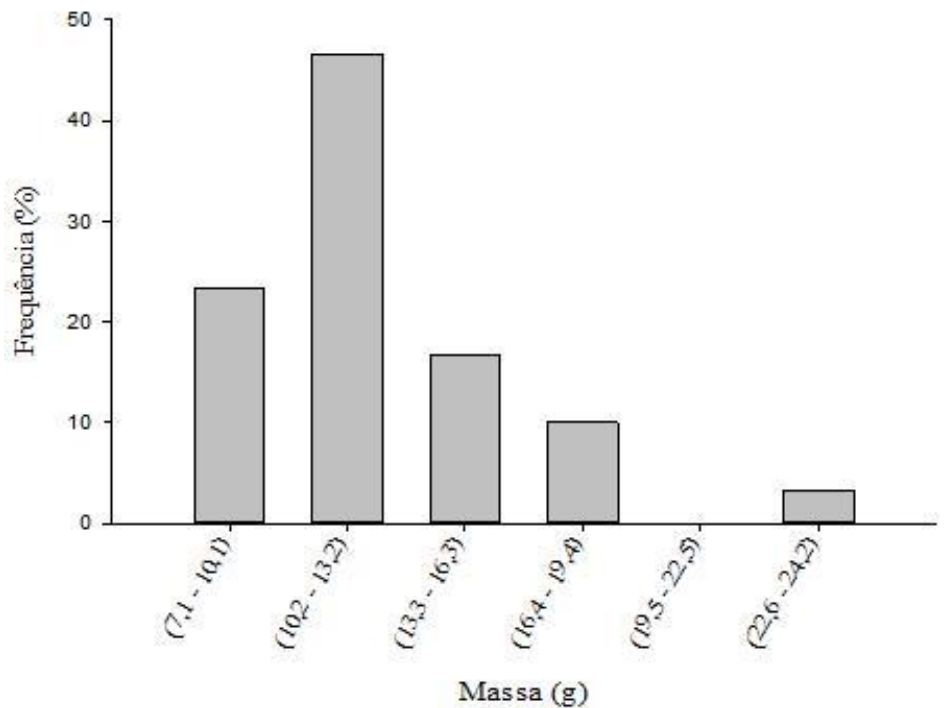

Figura 3. Massa de frutos de pau ferro coletados em Vitória da Conquista-BA, 2015. 
Tabela 2. Comprimento, espessura e largura de cem sementes de pau ferro, localizados em Vitória da Conquista - BA, 2015.

\begin{tabular}{lccc}
\hline Parâmetro & $\begin{array}{c}\text { Comprimento } \\
(\mathrm{mm})\end{array}$ & $\begin{array}{c}\text { Largura } \\
(\mathrm{mm})\end{array}$ & $\begin{array}{c}\text { Espessura } \\
(\mathrm{mm})\end{array}$ \\
\hline Média & $10,2 \pm 0,9$ & $7,1 \pm 0,8$ & $4,0 \pm 0,5$ \\
Mediana & 10,3 & 7,2 & 4,1 \\
Variância & 0,7 & 0,7 & 0,2 \\
\hline CV $(\%)$ & 8,5 & 11,8 & 12,5 \\
\hline
\end{tabular}

O comprimento, largura e espessura das sementes variaram de 7,8 a $12,2 \mathrm{~mm} ; 1,2$ a $8,7 \mathrm{~mm}$ e 2,3 a 4,8 $\mathrm{mm}$, respectivamente. Uma maior quantidade de sementes foi observada apresentando valores de comprimento entre 10,3 a $10,7 \mathrm{~mm}$; largura de 7,1 a 7,8 mm e espessura de 4,3 a 4,5 mm, sendo estes valores da ordem de 26\%, 46\% e $24 \%$ (Figura 4).

$\mathrm{O}$ número de sementes por fruto variou de duas a sete, sendo verificada média de cinco sementes por fruto (Tabela 2). Galdino et al. (2007) verificaram de seis a doze sementes presentes em frutos de pau ferro predominando nove sementes por fruto. $\mathrm{O}$ número de sementes por fruto pode aumentar ou diminuir em função da eficiência do processo de polinização, ou seja, quanto maior a quantidade de grãos de pólen viáveis e compatíveis que alcançam o estigma da flor, maior será

o número de óvulos fertilizados e consequentemente a produção de sementes (NASCIMENTO et al., 2011). Também ocorreu variação quanto à massa de sementes encontradas por fruto, havendo uma amplitude de $1,7 \mathrm{~g}$ entre o valor mínimo e máximo encontrado (Tabela 3).

A maioria dos frutos (57\%) apresentou massa de sementes variando entre 0,5 e $0,8 \mathrm{~g}$, paralelamente foi observada a menor quantidade de frutos (3\%) apresentando valores de massa de sementes entre 1,7 e 2,0g (Figura 5). Estes valores contribuíram para que o peso médio final das sementes fosse de $0,8 \mathrm{~g}$. Dentro da mesma espécie, existem variações individuais devidas às influências de fatores bióticos e abióticos, durante o desenvolvimento das sementes e à variabilidade genética (SANTOS et al., 2009).

Tabela 3. Valores mínimos, máximos e médios de características físicas de sementes de pau ferro, localizados em Vitória da Conquista - BA, 2015.

\begin{tabular}{lccc}
\hline \multicolumn{1}{c}{ Característica } & Mínimo & Máximo & Média \\
\hline $\begin{array}{l}\text { Número de sementes } \\
\text { por fruto }\end{array}$ & 2 & 7 & $5 \pm 0,2$ \\
$\begin{array}{l}\text { Massa de sementes } \\
\text { por fruto(g) }\end{array}$ & 0,3 & 2,0 & $0,8 \pm 0,3$ \\
\hline
\end{tabular}
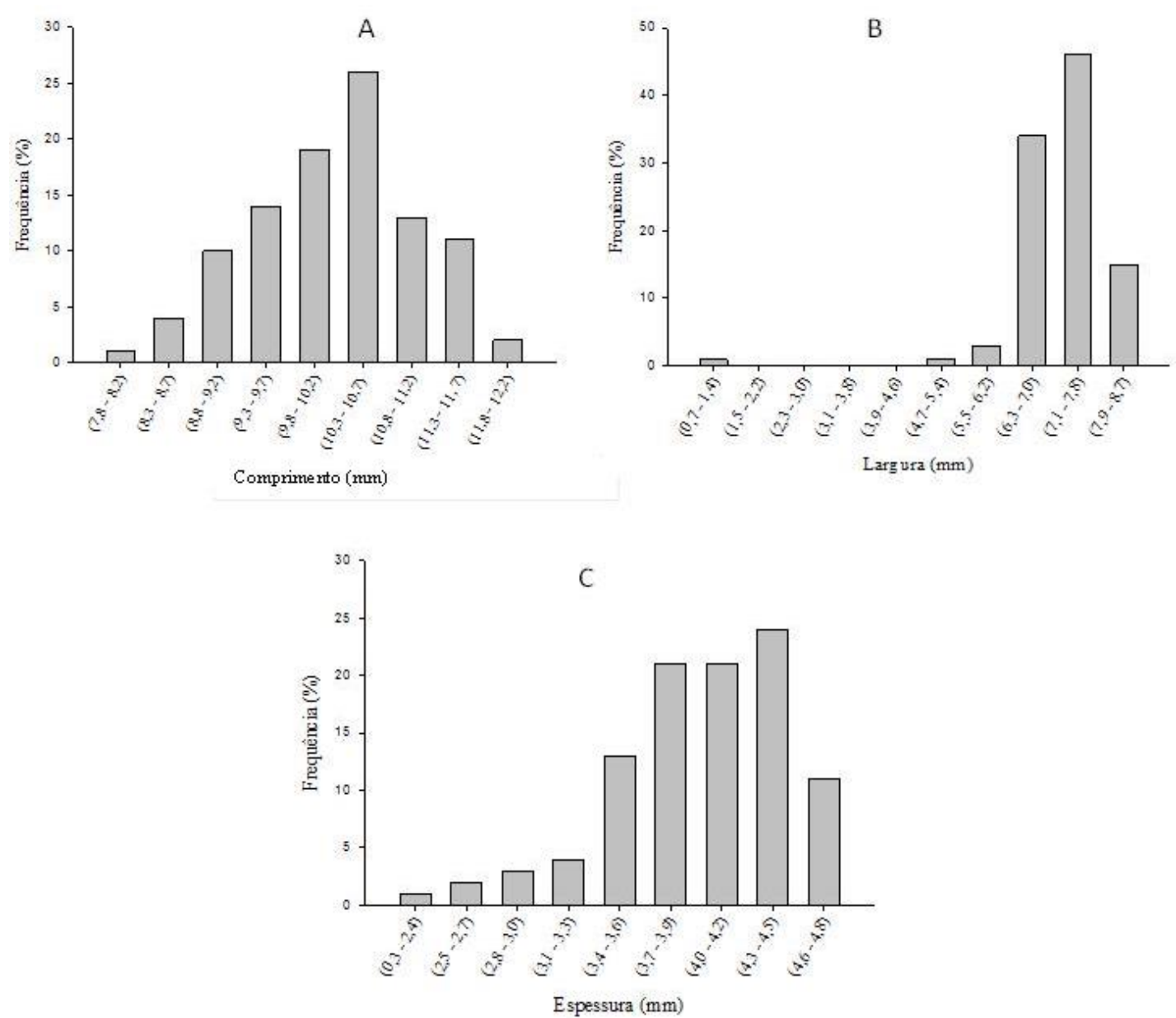

Figura 4. Histogramas de frequência (\%) para as características de comprimento (A), largura (B) e espessura (C) de sementes de pau ferro, coletados em Vitória da Conquista-BA, 2015. 
A massa é uma característica que pode ser considerada indicadora da qualidade fisiológica das sementes, sendo que as mais pesadas apresentam maior vigor durante o período de germinação. Alguns estudos mostram que a massa da semente influencia as taxas de germinação e o vigor de plantas jovens, dentro de uma mesma espécie (COSTA et al., 2006; KLEIN et al., 2007).

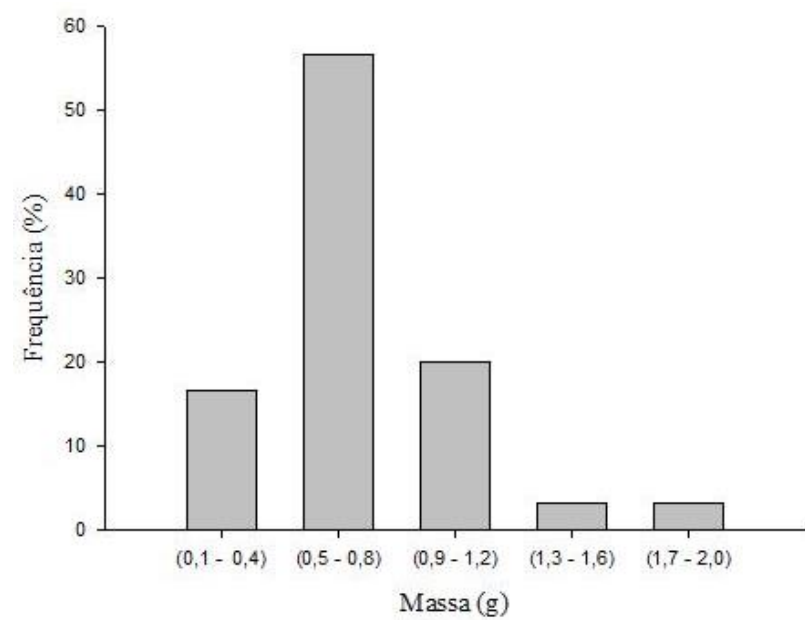

Figura 5. Massa de sementes de pau ferro coletados em Vitória da Conquista-BA, 2015.

As variações ocorridas nas características estudadas podem estar relacionadas tanto com fatores genéticos, quanto com as condições de solo em que a planta mãe se encontrava, haja vista que o ambiente no qual a árvore matriz está inserida tem forte influência sobre o tamanho das sementes produzidas (SHEN et al., 1981). Estas variações de aspecto comportamental morfológico são de grande importância em estudos de melhoramento genético pois promovem a variabilidade genética dentro de populações em uma mesma espécie.

\section{Conclusões}

Os valores biométricos observados no estudo são indicativos que os frutos e sementes de Caesalpinia ferrea Mart. ex Tul. apresentam variabilidade genética em suas características avaliadas.

\section{Referências Bibliográficas}

BATTILANI, J. L.; SANTIAGO, E. F.; DIAS, E. S. Morfologia de frutos, sementes, plântulas e plantas jovens de Guibourtia hymenifolia (Moric.) J. Leonard (Fabaceae). Revista Árvore, Viçosa-MG, v. 35, n.5, p. 1089-1098, 2011.

BEZERRA, F. T. C.; ANDRADE, L. A.; BEZERRA, M. A. F.; SILVA, M. L. M.; M. A. F.; NUNES, R. C. R; COSTA, E. G. Biometria de frutos e sementes e tratamentos prégerminativos em Cassia fistula L. (FabaceaeCaesalpinioideae). Semina: Ciências Agrárias, Londrina-PR, v. 35 , n. 4 , p. 2273-2286, 2014.
BEZERRA, F. T. C.; ANDRADE, L. A.; BEZERRA, PEREIRA, W. E.; FABRICANTE, J. R.; OLIVEIRA, L. S. B.; FEITOSA, R. C. Biometry of fruits and seeds and pregermination treatments in Cassia grandis L. f. (Fabaceae). Semina: Ciências Agrárias, Londrina, v. 33, suplemento 1, p. 2863-2876, 2012.

CÂMARA, F. A. A.; TORRES, S. B.; GUIMARÃES, I. P.; OLIVEIRA, M. K. T.; OLIVEIRA, F. A. Biometria de frutos e sementes e superação de dormência de jucá Caesalpinia ferrea mart. ex Tul (Leguminosae - Caesalpinoideae). Caatinga, Mossoró-RN, v.21, n.4, p.172-178, 2008.

CARVALHO, N. M.; NAKAGAWA, J. Sementes: ciência, tecnologia e produção. 4. ed. Jaboticabal-SP: FUNEP, 2000. $588 \mathrm{p}$.

CAVALHEIRO, M. G., FARIAS, D. F., GEORGIA, S. F., EDSON, NUNES, E. P., CAVALCANTI, F. S., ILKA, M. V., MELO, V. M. M., CARVALHO, A. F. U. Atividades biológicas e enzimáticas do extrato aquoso de sementes de Caesalpinia ferrea Mart., Leguminosae. Revista Brasileira de Farmacognosia, Brasília-DF, v.19, n.2, p.586-591, 2009.

CHRISTRO, L. F.; AMARAL, J. F. T.; LAVIOLA, B. G.; MARTINS, L. D.; AMARAL, C. F. Biometric analysis of seeds of genotypes of physic nut (Jatropha curcas L.). Agropecuária Científica no Semiárido, Campina GrandePB, v.8, n.1, p.01-03, 2012.

COELHO, M. F. B.; MAIA, S. S. S.; OLIVEIRA, A. K.; DIÓGENES, F. E. P. Superação da dormência tegumentar em sementes de Caesalpinia ferrea Mart ex Tul. Revista Brasileira de Ciências Agrárias. Recife-PE, v.5, n.1, p.7479, 2010.

COSTA, R. S.; OLIVEIRA, I. V. M.; MÔRO, F. V.; MARTINS, A.B.G. Aspectos morfológicos e influência do tamanho da semente na germinação do jambo-vermelho. Revista Brasileira de Fruticultura, Jaboticabal - SP, v.28, n.1, p.117-120, 2006.

FERREIRA, R. A.; BARRETO, S. S. B. Caracterização morfológica de frutos, sementes, plântulas e mudas de paubrasil (Caesalpinia echinata Lamarck). Revista Árvore, Viçosa-MG, v.39, n.3, p.505-512, 2015.

GALDINO, G.; MESQUITA, M. R.; FERRAZ, I. D. K.; Descrição morfológica da plântula e diásporos de Caesalpinia ferrea Mart. Revista Brasileira de Biociências, Porto AlegreRS, v. 5, n. 2, p. 747-749, jul. 2007.

GUSMÃO, E.; VIEIRA, F. A.; FONSECA-JUNIOR, E. M. Biometria de frutos e endocarpos de murici (Byrsonima verbascifolia Rich. ex A. Juss.). Cerne, Lavras- MG, v.12, n.1, p.84-91, 2006.

INMET. INSTITUTO NACIONAL DE METEOROLOGIA. Disponível em: 〈http://www.inmet.gov.br>. Acesso em: 10 ago. 2004.

KLEIN, J.; ZUCARELI, V.; KESTRING, D.; CAMILLI, L.; RODRIGUES, J. D. Efeito do tamanho da semente na emergência e desenvolvimento inicial de mudas de pitangueira (Eugenia uniflora L.). Revista Brasileira de Biociências, Porto Alegre- RS, v. 5, n. 2, p. 861-863, 2007. 
MAIA, G. N. Caatinga: árvores e arbustos e suas utilidades. 1. ed. São Paulo-SP: D\&Z Computação Gráfica, 2004. 413 p.

MATHEUS, M. T.; LOPES, J. C. Morfologia de frutos, sementes e plântulas e germinação de sementes de Erythrina variegata L. Revista Brasileira de Sementes, Londrina- PR, v. 29, n. 3, p. 08-17, 2007.

NASCIMENTO, W. N.; LIMA, G. P.; CARMONA, R. Influência da quantidade de pólen na produção e qualidade de sementes híbridas de abóbora. Horticultura brasileira, Brasília-DF, v. 29, n. 1, p. 29-25, 2011.

NOGUEIRA, N. W.; MARTINS, H. V. G.; BATISTA, D. S.; RIBEIRO, M. C. C. Grau de dormência das sementes de jucá em função da posição na vagem. Revista Verde de Agroecologia e Desenvolvimento Sustentável, Mossoró- RN, v. 5, n. 1, p. $39-42,2010$.

OLIVEIRA, M. S.; SANTANA, D. G.; SANTOS, C. M. Biometria de frutos e sementes e emergência de plântulas de duas espécies frutíferas do gênero Campomanesia. Revista Brasileira de Fruticultura, Jaboticabal-SP, v. 33, n. 2, p. 446-455, 2011.

PEREIRA, S. R.; GIRALDELLI, G. R.; LAURA, V. A.; SOUZA, A. L. T. Tamanho de frutos e de sementes e sua influência na germinação de jatobá-do-cerrado (Hymenaea stigonocarpa var. stigonocarpa Mart. Ex Hayne, leguminosae - Caesalpinoideae). Revista Brasileira de Sementes, Londrina- PR, v. 33, n. 1 p. 141 - 148, 2011.
SANTOS, A. R. F., SOUZA, E. M., MANN, R. S., FERREIRA, R. A., SILVA, A. V. C. Perfis Enzimáticos de Genótipos de Caesalpinia férrea var. leyostachiae Cassia grandis.Floresta e Ambiente, Rio de Janeiro- RJ, v.17, n.1, p.37-43, 2010

SANTOS, F. S.; PAULA, R. C.; SABONARO, D. Z.; VALADARES, J.; Biometria e qualidade fisiológica de sementes de diferentes matrizes de Tabebuia chrysotricha (Mart. Ex A. DC.) Standi, Scientia Forestalis, Piracicaba-SP, v. 37, n. 82, p. 163-173, 2009.

SEI. SUPERINTENDÊNCIA DE ESTUDOS ECONÔMICOS E SOCIAS DA BAHIA. Estatística dos municípios Baianos. Brumado-BA: v. 4, n.1, 2013. p. 435-454. Disponível em: <http://www.sei.ba.gov.br/>. Acesso em: 22 fev. 2017.

SHEN, H. H., RUDIN, D.; LINDGREN, D. Study of the pollination pattern in a Scots pine seed orchard by means of isozyme analysis. Silvae Genet, Colorado, v. 30, n. 1, p. 7-15, 1981. 